\title{
UU Khusus LPP: Solusi Transformasi RRI-TVRI
}

\author{
Masduki \\ Dosen Program Studi Ilmu Komunikasi Universitas Islam Indonesia Yogyakarta; \\ Pendiri Rumah Perubahan Lembaga Penyiaran Publik; \\ Direktur Program dan Produksi LPP RRI periode 2010-2012.
}

\begin{abstract}
According to Broadcasting Law Number 32 Year 2002, Radio Republik Indonesia (RRI) and Televisi Republik Indonesia (TVRI) have become independent public service broadcasting institutions. Until 2012, the transformation of both still faces some obstacles, internally and externally. Both are still encountering identity crisis whether representing public or authority due to strong influence of power-not fully free from government intervention, problem of civil servants professionalism, and budget nomenclature. There is the need for a new and special law of public broadcasting in order to ensure protection and transformation of RRI and TVRI as public service broadcasting in the future.
\end{abstract}

Keywords: public, broadcasting, transformation, RRI, TVRI

\begin{abstract}
Abstrak
Berdasarkan Undang-Undang Penyiaran No. 32/2002, Radio Republik Indonesia (RRI) dan Televisi Republik Indonesia (TVRI) telah menjadi lembaga penyiaran publik. Sampai tahun 2012, transformasi dari kedua lembaga ini masih menghadapi berbagai hambatan, dari dalam maupun luar. RRI maupun TVRI masih mengalami krisis identitas apakah murni menjadi representasi publik atau melayani penguasa, karena masih kuatnya pengaruh kekuasaan - tidak benar-benar bebas dari intervensi pemerintah, masalah profesionalisme PNS, dan permasalahan keuangan. Muncul kebutuhan untuk membuat regulasi yang baru dan khusus mengatur penyiaran publik. Tujuannya adalah untuk memastikan perlindungan dan perubahan RRI dan TVRI sebagai lembaga penyiaran publik di masa depan.
\end{abstract}

Kata Kunci: publik, penyiaran, perubahan, RRI, TVRI

\section{Pendahuluan}

Diskusi rutin Rumah Perubahan Lembaga Penyiaran Publik (RPLPP) pertengahan Mei 2013 mengupas topik membedah draft RUU Penyiaran versi pemerintah. Dalam draft ini, ada tiga isu penting terkait LPP. Pertama, LPP-menurut draft pemerintah yang diwakili Kementerian Komunikasi dan Informasi (Kominfo)didirikan oleh Pemerintah, bukan oleh negara. Kedua, LPP berbentuk Badan Layanan Umum (BLU) di bawah kementerian, bukan lembaga negara yang langsung bertanggung jawab kepada Presiden. Ketiga, LPP diusulkan akan diatur lebih rinci dalam peraturan pemerintah (PP), bukan dalam UU tersendiri sebagaimana kehendak Komisi I DPR selaku representasi publik. 
Peserta diskusi termasuk penulis sepakat menyimpulkan bahwa pemerintah, setidaknya tercermin dari draft RUU Penyiaran, cenderung berpikir pragmatis jangka pendek: menghadirkan kembali pemikiran otoriter untuk menjadikan "LPP sebagai bukan LPP”, melainkan sebagai corong kekuasaan sentralistik. Ini merupakan sebuah langkah mundur dibanding dengan UU Penyiaran No. 32/2002. Berbeda 180 derajat dengan gagasan DPR yang melompat jauh ke depan: mengusulkan UU khusus LPP. Draft versi pemerintah membangkitkan kembali reaksi publik yang sempat "tertidur" selama 12 tahun. Tulisan ini hendak mengurai kembali stand point LPP secara universal, dan merekomendasikan masyarakat sipil mendorong dibahasnya UU khusus LPP sebagai solusi komprehensif.

\section{Pilihan Lembaga Penyiaran Publik}

Wacana tentang lembaga penyiaran publik atau public service broadcasting telah berkembang di Amerika dan Inggris sejak awal tumbuhnya lembaga penyiaran tahun 1920-an. LPP bukan sebagai alternatif atau pilihan di antara berbagai bentuk lembaga penyiaran, melainkan merupakan bentuk asli dari lembaga penyiaran itu sendiri, sebelum bertransformasi dan membiak menjadi fenomena yang mengglobal saat ini. Untuk pertama kalinya, British
Broadcasting Corporation (BBC) lahir sebagai lembaga penyiaran yang melayani kepentingan publik. Tokoh di balik sukses $B B C$ adalah John Reith yang memperkenalkan berbagai pemikiran substansial tentang nilai-nilai LPP. Banyak negara demokratis di dunia kemudian menjadikan $B B C$ sebagai model LPP yang sukses berjaringan, termasuk Indonesia.

Model lain adalah National Public Radio (NPR) di Amerika Serikat, jaringan antar radio publik lokal yang beroperasi sejak tahun 1970-an di bawah regulasi khusus Public Broadcasting Act of 1967. UU ini juga memayungi keberadaan CPB atau Corporation for Public Broadcasting. Melalui teknologi satelit, distribusi program berkualitas dilakukan radio anggota jaringan NPR. Anggota jaringan pun melakukan diseminasi kepada publik, di samping memproduksi programnya masing-masing untuk menjamin lokalitas, serta untuk berkompetisi dengan radio swasta. Dari segi manajemen konten, model NPR bersifat buttom-up, otonom, dan dinilai tepat bagi negara kepulauan seperti Indonesia.

Pemikiran lembaga penyiaran publik telah berakar kuat pada prinsip negara demokratis, mengakomodasi kondisi empirik dan ideal diversitas publik dari beragam sisi: kebutuhan dasar, etnisitas, aspirasi politik, geografis, dan sosial budaya. Siaran LPP bertujuan memperbaiki kualitas hidup masyarakat 
melalui berita dan informasi (transmit programming that aims to improve society by informing viewers), sebuah misi yang kontras dibanding lembaga penyiaran komersial yang hanya memberikan suguhan siaran atraktif, menghibur, mengundang budaya konsumtif agar relevan bagi bisnis periklanan. Karena tujuan itu, maka status hukum, bentuk lembaga, sumber pendanaan dan standar sumber daya manusia yang dimiliki LPP harus pula mencerminkan sifat demokratis, terbuka, kesukarelaan dan kesetaraan di semua sektor (Mendel, 2000).

Tiga ciri penting LPP dari segi eksistensi dan konten adalah: Pertama, geographic universality: stasiun siarannya harus menjangkau secara teknis dan konten ke seluruh wilayah negara tanpa kecuali, melayani semua kepentingan (catering for all interests and tastes), termasuk kelompokkelompok minoritas melalui saluran dan program khusus. LPP juga harus peduli dan menjadi cermin identitas nasional sebuah negara beserta keragaman komunitasnya. Kedua, LPP membangun budaya kompetisi berbasis program berkualitas, mengabaikan rating kuantitas dari pemirsa/pendengarnya. Jumlah khalayak tetap penting akan tetapi kualitas program lebih penting. Secara rasional ini semestinya menciptakan khalayak cerdas, karena kualitas program ini tak hanya berkorelasi dengan minat tetapi kebutuhan khalayak. Ketiga, independen dari campur tangan pemerintah yang sedang berkuasa maupun dari kepentingan bisnis. Program siaran sebagai layanan output LPP harus mencerminkan kesetaraan, oleh karena itu institusinya harus tidak mendapat tekanan komersial dan atau kontrol rezim politik yang sedang berkuasa (Mendel, 2000).

Penting dicatat, terdapat perbedaan signifikan antara kondisi ideal yang dikonsepsikan LPP, pengalaman di Inggris dan Amerika dengan kondisi historis-empirik perkembangan LPP di Indonesia. Ini bisa dimengerti karena penyiaran publik TV dan radio adalah sebuah sistem operasi media yang tidak berada di ruang hampa. Media massa termasuk LPP adalah institusi sosial yang kompleks. Denis McQuail menggambarkan media massa mencakup beragam aspek sejak manajerial, SDM professional, hingga teknik. Ia menjelaskan bahwa media penyiaran berinteraksi dan dipengaruhi oleh organisasi sosial, ekonomi dan politik, peristiwa di masyarakat dan khalayak sehingga perlu proteksi regulasi yang kuat.

Di banyak negara, terdapat hubungan yang erat antara struktur sosial dengan sistem media massa. Dalam struktur sosial yang didasarkan pada sistem politik dan ekonomi tertentu, terdapat hubungan antarsistem yang sangat dipengaruhi oleh sistem media yang dikembangkan. Sebaliknya, sistem media juga dipengaruhi atau dibentuk 
secara paradigmatik oleh struktur sosial. Sistem media massa merupakan sebuah sarana pengendali sosial untuk menyeimbangkan sistem secara keseluruhan. Keberlangsungan sistem penyiaran senantiasa berkarakter tertentu berdasarkan struktur sosial, apakah ia demokratis atau otoritarian.

Dalam konteks ekonomi-politik, ada tiga sistem penyiaran yang beroperasi di dunia. Yaitu sistem penyiaran otoriter, neoliberal, dan sistem penyiaran demokratis. Kategorisasi ini sangat erat kaitannya dengan teori pers klasik yang dikembangkan oleh F. Siebert yaitu: a) Authoritarian theory; b) Libertarian theory; c) Communist theory; d) Social Responsibility theory (S. Siebert, dikutip McQuail, 1994).

Teori pertama yaitu teori media otoritarian bercirikan pers sebagai alat propaganda pemerintah. Fungsi media adalah menjustifikasi kebenaran pendapat pemerintah terhadap berbagai persoalan yang muncul di masyarakat. Media boleh mengkritik sejauh tak bertentangan dengan status quo rezim yang berkuasa. Otoritas perizinan media ada di tangan pemerintah. Izin dapat dicabut secara sepihak setiap saat dan sensor isi dilakukan secara ketat. Kedua, teori media komunis bercirikan tidak diperkenankannya kepemilikan media secara pribadi. Media menyebarkan pandangan yang terutama bersumber dari ucapan pejabat negara.
Ketiga, teori media liberal sebagai antitesa teori otoritarian. Ciri teori ini, media bukan alat pemerintah. Media bebas dimiliki dan dioperasikan siapapun. Hukum pasar bebas membuat kepemilikan media hanya terpusat pada sekelompok pemodal besar yang mengakumulasi keuntungan. Liberalisasi penyiaran menyebabkan kontrol terhadapnya berada di tangan para pemilik modal bukan khalayak luas.

Untuk menjawab kondisi itu muncul teori keempat, yaitu teori pers tanggung jawab sosial. Teori ini merupakan pengembangan sekaligus kritik terhadap teori media liberal. Media harus lepas dari intervensi pemerintah dan kepemilikan media yang monopolistik dan dampaknya terhadap potensi manipulasi informasi oleh kekuatan modal harus diantisipasi dengan regulasi. Dari sini berakarlah filosofi diversity of ownership dan diversity of content yang populer dalam studi mengenai media penyiaran.

Penciptaan ruang publik (public sphere) menjadi dasar teori tanggung jawab sosial. Media harus menjamin kesetaraan akses semua pihak untuk berbicara lewat media sebab kontrol media diletakkan pada opini masyarakat, preferensi konsumen dan standar profesional. Untuk menjamin kepentingan umum, dimungkinkan adanya intervensi negara secara terbatas. Dalam teori tanggung jawab sosial dikenal badan 
independen yang akan memantau dan menilai fungsi sosial penyiaran.

Empat teori media ini dikembangkan lagi oleh Denis McQuail menjadi enam dengan menambahkan teori media pembangunan dan demokratik partisipan. Media pembangunan menempatkan diri sebagai pendorong transisi dari keterbelakangan dan penjajahan ke independensi dan kondisi materi yang lebih baik dengan mengedepankan semangat membangun infrastruktur dan kemampuan finansial. Media massa di banyak negara berkembang menganut teori ini dengan orientasi berita yang tinggi terhadap sukses pembangunan ekonomi, sosial budaya dan politik.

Karena tekanan fungsi sebagai media pembangunan, sikap kritis dan kebebasan wartawan menyampaikan sisi buruk dari pembangunan menghadapi kendala. Sehingga muncul teori media demokratik partisipan sebagai antitesa dari teori media pembangunan yang bercirikan antidominasi oleh media besar dan monopoli pemilikan oleh individu ataupun publik tertentu (private and public monopolies). Teori ini berciri pemenuhan hak informasi lokal yang relevan, hak untuk berinteraksi dalam skala media kecil dalam skala komunitas, kelompok kepentingan atau subkultur. Dalam praktik, teori ini ditandai terbitnya media alternatif (alternative or underground press), televisi atau radio komunitas dengan atau tanpa kabel, media mikro seperti media antartetangga, poster dinding dan media untuk perempuan atau minoritas etnik (McQuail, 1994).

Teori-teori tersebut dalam praktik mengalami pergeseran dan percampuran aplikasi sehingga sulit mengidentifikasi suatu negara menganut teori media tertentu secara mutlak. Meski begitu integrasi itu hanya dapat berlangsung ke dalam dua. Pertama, teori media libertarian yang dilanjutkan oleh teori media tanggung jawab sosial dan demokratik partisipan. Kedua, teori media otoritarian yang berkembang segaris dengan teori media komunis dan teori media pembangunan. Riset penulis terhadap UU Penyiaran No. 32/2002 menemukan tiga pemikiran sistem media: otoriter, liberal, dan demokratik yang saling bercampur aduk sebagaimana diuraikan sebagai berikut: 
Tabel 1. Perbandingan Tiga Pemikiran Sistem Penyiaran

\begin{tabular}{|c|c|c|c|}
\hline Regulasi & Otoritarian & Neoliberal & Demokratis \\
\hline $\begin{array}{l}\text { Orientasi dan } \\
\text { Bentuk Lembaga }\end{array}$ & $\begin{array}{l}\text { Media organik } \\
\text { pemerintah, politisasi } \\
\text { media publik }\end{array}$ & $\begin{array}{l}\text { Media komersial, } \\
\text { komersialisasi media } \\
\text { pemerintah dan publik }\end{array}$ & $\begin{array}{l}\text { Media publik, publikisasi } \\
\text { media penyiaran } \\
\text { pemerintah }\end{array}$ \\
\hline $\begin{array}{l}\text { Lembaga } \\
\text { Regulator }\end{array}$ & $\begin{array}{l}\text { Perlu oleh pemerintah } \\
\text { atau badan bentukan } \\
\text { pemerintah yang } \\
\text { bertanggung jawab } \\
\text { kepada pemerintah }\end{array}$ & $\begin{array}{l}\text { Tidak perlu, } \\
\text { diserahkan kepada } \\
\text { mekanisme pasar } \\
\text { melalui asosiasi } \\
\text { penyiaran komersial }\end{array}$ & $\begin{array}{l}\text { Perlu oleh badan } \\
\text { independen yang dibentuk } \\
\text { negara bertanggung jawab } \\
\text { kepada publik }\end{array}$ \\
\hline Status Frekuensi & $\begin{array}{l}\text { Milik publik yang } \\
\text { dikuasai penuh oleh } \\
\text { pemerintah atas nama } \\
\text { negara }\end{array}$ & $\begin{array}{l}\text { Milik publik dikelola } \\
\text { secara komersial oleh } \\
\text { pemilik modal }\end{array}$ & $\begin{array}{l}\text { Milik publik yang dikelola } \\
\text { oleh badan independen atas } \\
\text { nama negara }\end{array}$ \\
\hline $\begin{array}{l}\text { Partisipasi } \\
\text { publik penyiaran }\end{array}$ & $\begin{array}{l}\text { Lemah, semua urusan } \\
\text { diklaim sepihak oleh } \\
\text { pemerintah }\end{array}$ & $\begin{array}{l}\text { Lemah, semua sektor } \\
\text { penyiaran dikuasai } \\
\text { oleh pemilik modal }\end{array}$ & $\begin{array}{l}\text { Kuat, langsung atau melalui } \\
\text { lembaga independen }\end{array}$ \\
\hline $\begin{array}{l}\text { Tujuan regulasi } \\
\text { berbentuk UU } \\
\text { dan PP }\end{array}$ & $\begin{array}{l}\text { Mengatur agar tetap ada } \\
\text { peluang politisasi media } \\
\text { penyiaran }\end{array}$ & $\begin{array}{l}\text { Mengatur agar terbuka } \\
\text { peluang komersialisasi, } \\
\text { privatisasi }\end{array}$ & $\begin{array}{l}\text { Mengatur agar terjamin } \\
\text { akses publik secara merata } \\
\text { dan adil }\end{array}$ \\
\hline $\begin{array}{l}\text { Monopoli isi dan } \\
\text { pemilikan }\end{array}$ & $\begin{array}{l}\text { Boleh selama bisa } \\
\text { dikendalikan } \\
\text { pemerintah }\end{array}$ & $\begin{array}{l}\text { Harus untuk } \\
\text { mendorong akumulasi } \\
\text { kapital }\end{array}$ & $\begin{array}{l}\text { Tidak boleh karena anti- } \\
\text { keberagaman dan } \\
\text { kebebasan berekspresi }\end{array}$ \\
\hline $\begin{array}{l}\text { Intervensi Asing } \\
\text { dalam } \\
\text { permodalan dan } \\
\text { sebagainya }\end{array}$ & $\begin{array}{l}\text { Tidak boleh karena } \\
\text { dianggap intervensi } \\
\text { asing, anti-pemerintah }\end{array}$ & $\begin{array}{l}\text { Boleh karena } \\
\text { mendorong efisiensi } \\
\text { lembaga penyiaran } \\
\text { secara komersial }\end{array}$ & $\begin{array}{l}\text { Tidak boleh atau dibatasi } \\
\text { atau bersifat sementara } \\
\text { memproteksi kepentingan } \\
\text { local }\end{array}$ \\
\hline
\end{tabular}

\section{Belajar dari Sejarah}

Memasuki tahun 1990-an, terdapat fenomena global tergerusnya keberadaan LPP di negara-negara penganut ekonomi liberal seperti Inggris, termasuk berdampak sampai ke Indonesia. Bahkan di Indonesia, tergerusnya posisi dan relevansi LPP tidak hanya sebagai dampak dari menguatnya ekonomi pasar, privatisasi badan publik, akan tetapi diakibatkan pula oleh faktor stigma historis agen penguasa Orde Baru yang belum hilang, baik di benak broadcaster LPP sendiri maupun kalangan pengambil keputusan.

Stigma dan romantisme sebagai agen pemerintah bahkan cenderung dipelihara secara sistimatis melalui budaya birokrasi yang kental feodalisme dalam rutinitas kerja dan penentuan 
jabatan. Ketentuan dalam UU Penyiaran No. 32/2002 yang menegaskan posisi dan keberadaan LPP hingga tahun 2013 menunjukkan perubahan signifikan pada akses publik berkiprah di manajemen dan konten siaran, akan tetapi belum mampu mengubah secara radikal pola pikir paternalistik. Hasrat pemerintah pusat dan daerah untuk menggunakannya sebagai media propaganda pun belum bisa terbendung.

Liberalisasi ekonomi penyiaran di Indonesia menyebabkan tidak imbangnya proporsi jumlah lembaga penyiaran antara publik, komersial, dan komunitas. Kondisi ini dapat dicermati pada rekapitulasi lembaga penyiaran sampai bulan Juni 2013:

Tabel 2. Rekapitulasi Lembaga Penyiaran

\begin{tabular}{clc}
\hline Media & Bentuk & Jumlah \\
\hline Televisi & Swasta & 439 \\
& Publik & 11 \\
& Komunitas & 11 \\
& Berlangganan & 182 \\
& & \\
Radio & Swasta & 1828 \\
& Publik & 75 \\
& Komunitas & 129 \\
TOTAL & & $\mathbf{2 6 7 5}$ \\
\hline
\end{tabular}

Sumber: KPI Pusat, 2013

Di tengah kuatnya cengekraman industri penyiaran komersial, LPP khususnya TVRI kerapkali tergoda untuk mengakomodasi model kemasan dan konten siaran yang kemudian menjauhkannya dari misi kepublikan. Muncul persepsi, siaran TVRI hampir mirip dengan siaran TV swasta. Fenomena ini bisa dipahami, karena setelah modernisasi media global di tahun 1980an, maka muncul pemikiran alternatif model baru LPP yang disebut a mixed commercial and public model. Di Kanada, model ini diadopsi secara terbatas oleh
CBC yang membuka peluang pendapatan melalui iklan komersial-karenanya harus menyajikan program yang populer, rendah mutunya-untuk melengkapi subsidi pemerintah yang terbatas. Fenomena serupa kemudian diadopsi RRI dan TVRI yang memberikan ruang alokasi 15 persen untuk iklan komersial.

Sebagai negara yang memilih menganut sistem demokrasi, maka pilihan menjadikan RRI dan TVRI sebagai LPP yang bersifat non-profit dan independen adalah konsekuensi dari kebebasan pers. Secara historik, RRI-TVRI mengalami 
perubahan kelembagaan yang berbeda jauh dengan pola kelahiran $B B C$ di Inggris, NPR di Amerika, $A B C$ di Australia. Mungkin hanya di Indonesia, sebuah institusi penyiaran mengalami metamorfosa hingga tiga kali. Reformasi politik tahun 1998 mengubah drastis status kelembagaan dan orientasi operasional RRI dan TVRI. Identitas sebagai stasiun plat merah tamat secara yuridis seiring keluarnya UU No. 32/2002 tentang Penyiaran.

Meskipun akhirnya TVRI dan RRI menjadi media penyiaran publik, namun dalam masa transisi antara 1998-2004 bahkan hingga tahun 2013, pemerintah telah menerapkan beragam model kelembagaan, melakukan akrobat "tarik ulur" atas TVRI dan RRI, mulai dengan pilihan menjadi perseroan terbatas untuk TVRI dan RRI sebagai perusahaan jawatan hingga mendorong kembali menjadi unit pelaksana teknis di bawah Kementerian Kominfo. Kebijakan yang menunjukkan kebingungan sikap atas status lembaga tersebut, apakah akan secara murni dilakukan liberalisasi, otorianisasi, atau publikisasi.

Secara historis, LPP di Indonesia memiliki empat era yang menunjukkan kuatnya pengaruh kekuatan politik dan ekonomi eksternal terhadap nasibnya. Era pertama ketika RRI dan TVRI lahir dan dijadikan sebagai alat menyebarluaskan semangat kemerdekaan pada tahun 1945 dn 1952. Sebagai contoh, gelora nasionalisme 1945 yang kuat menyatu dengan kekuatan RRI sebagai radio yang mampu mengakses pelosok. RRI menjadi media suara kemerdekaan dan sikap anti kolonialisme. Era ini hanya bertahan hingga konsolidasi rezim Soekarno kuat dan ketika berlaku kebijakan demokrasi terpimpin.

Hampir 50 tahun lebih, RRI menjadi media propaganda politik elit yang berkuasa sejak rezim Soekarno berkuasa penuh dan diteruskan hingga era Orde Baru. Panjangnya masa kooptasi ini membuat stigma dan keyakinan yang sejati, melekat kuat di kalangan broadcaster-nya. Sejarah RRI dan juga TVRI sesungguhnya adalah sejarah sebagai medium untuk propaganda kekuasaan dan proteksi kekuasaan. Hal ini dilakukan dengan berbagai cara, seperti pemilihan program, penekanan fokus isu, diskusi lewat orang terseleksi kekuasaan, hingga menghindari penyiaran yang bersifat kritis. Ini terjadi karena status dan perannya di bawah Departemen Penerangan.

Era propaganda kekuasaan merupakan antiklimaks dari era media sosialisasi kemerdekaan dan berakibat pada merosotnya popularitas RRI sebagai media milik publik. Runtuhnya rezim Orde Baru tahun 1998 memengaruhi status dan orientasi pengelolaan RRI. Dari media yang dikuasai rezim Soeharto menjadi media yang secara politis mengambang oleh bubarnya instansi induknya, Departemen Penerangan. Era ketiga ini menempatkan RRI dan TVRI 
terombang-ambing dari media organik berpusat pada sistem pemerintahan yang relatif masih otoriter di era Habibie dan Gus Dur menjadi media komersial hingga menemukan "khittah-nya” sebagai LPP.

Tahun 2000-an, pilihan menjadi media komersial yang tetap dibiayai pemerintah akhirnya menjadi terwujud dalam status Perusahaan Jawatan. Sekali lagi era ini tidak menempatkan posisi publik sebagai aktor dominan. Baik kekuatan negara maupun pasar adalah kekuatan yang merepresi publik tercermin dari kuatnya program yang memberi ruang lebih besar kepada seremoni pemerintah disatu sisi dan kuatnya program yang mewadahi eksperimentasi pengiklan dan pemodal lain yang mampu membayar jam siar untuk promosi. Pergeseran status dan orientasi pengelolaan RRI TVRI mengalami puncaknya saat pengesahan UU No. 32/2002 tentang Penyiaran.

Riset Philip Kitley terhadap televisi tahun 2000 antara lain menyimpulkan, sejarah media penyiaran Indonesia senantiasa berkaitan dengan dua karakter utama yakni radio dan televisi swasta dan publik. Televisi dan radio swasta senantiasa berkait dengan perspektif sejarah kapitalisme, yakni suatu sistem produksi komoditas yang menjadikan korporasi swasta mampu memaksimalisasikan keuntungan mereka lewat sistem sponsor program-program yang sesuai dengan target pasar komoditasnya. Sedang TVRI di masa transisinya masih belum bergerak signifikan sebagai "cermin budaya ala pemerintah” (Kitley, 200o). Menarik untuk dicatat, pengalaman Amerika Serikat yang mampu mensintesiskan kapitalis dan struktur demokratisasi lewat kultur baru televisi.

Pilihan menjadikan RRI dan TVRI sebagai lembaga penyiaran publik merupakan keputusan strategis dan tepat bagi Indonesia. Namun demikian, belajar dari sejarah di atas, ternyata tidak hanya perubahan status yang dibutuhkan, tetapi juga perubahan manajemen dengan mengadopsi model yang sudah berkembang di luar negeri, lalu memformulasikannya dengan karakter lokal Indonesia yang multikultur. Rancangan UU Penyiaran pemerintah jelas akan menarik kembali posisi RRITVRI menjadi media otoriter, sebuah pilihan balik ke masa lalu yang mengingkari kehendak sejarah demokratisasi.

Secara teoritis, hanya ada tiga pilihan bentuk lembaga penyiaran, sebagaimana ditampilkan dalam tabel berikut. 
Tabel 3. Tiga Model Penyiaran Dunia

\begin{tabular}{clll}
\hline $\begin{array}{c}\text { Pemilikan } \\
\text { Media }\end{array}$ & \multicolumn{1}{c}{$\begin{array}{c}\text { Government Agency } \\
\text { (Penguasa) }\end{array}$} & $\begin{array}{c}\text { Government Corporation } \\
\text { (Publik) }\end{array}$ & \multicolumn{1}{c}{$\begin{array}{c}\text { Private } \\
\text { (Swasta) }\end{array}$} \\
\hline Tujuan & $\begin{array}{l}\text { Mobilization (Mobilisasi } \\
\text { Sosial-Politik) }\end{array}$ & $\begin{array}{l}\text { Education/Cultural } \\
\text { Enlightenment (Pendidikan, } \\
\text { Budaya, dan Penyadaran) }\end{array}$ & $\begin{array}{l}\text { Profit (Mencari } \\
\text { Untung) }\end{array}$ \\
Regulasi & Strong (Ketat) & Moderate (Sedang) & Weak (Lemah) \\
Pendanaan & $\begin{array}{l}\text { Government (Dana } \\
\text { Pemerintah) }\end{array}$ & $\begin{array}{l}\text { Licence Fee/Tax } \\
\text { Government Subsidy/ } \\
\text { Advertising (Pajak, Iuran, } \\
\text { Dana Pemerintah, dan Iklan) }\end{array}$ & $\begin{array}{l}\text { Advertising } \\
\text { (Periklanan) }\end{array}$ \\
& & Cultural/Educational/ & $\begin{array}{l}\text { Entertainment } \\
\text { (Hiburan) }\end{array}$ \\
& $\begin{array}{l}\text { Ideological/ } \\
\text { Cultural (Ideologis, } \\
\text { Budaya) }\end{array}$ & $\begin{array}{l}\text { Pendidikan, dan Hiburan) } \\
\text { Program }\end{array}$ & \\
\hline
\end{tabular}

Sumber: Dominick, 2001

Dua agenda pokok yang semestinya teratasi sepanjang tahun 2002-2013 adalah, pertama bagaimana mengubah stigma buruk di publik dan pejabat pemerintah pusat maupun daerah bahwa RRI dan TVRI media organik pemerintah dengan segala peran propagandisnya. Ini harus dilakukan dengan mengelola partisipasi publik agar mengisi program siaran tanpa tendensi untuk akumulasi kebutuhan modal atau akumulasi kebutuhan akses politik oleh elit pengelola RRI-TVRI. Kedua, mengubah budaya kerja dari gaya aparat pemerintah menjadi broadcaster profesional. Penuntasan dua agenda ini ternyata tidak mudah.

\section{Urgensi UU Khusus LPP}

Setelah 12 tahun UU Penyiaran No. 32/2002 diberlakukan, persoalan di lembaga penyiaran publik ternyata semakin kompleks, yang antara lain justru bersumber dari rumusan tentang LPP yang ada pada UU tersebut. Pada bab yang mengatur LPP disebutkan, Lembaga Penyiaran Publik adalah lembaga penyiaran yang berbentuk badan hukum, didirikan oleh negara, bersifat independen, netral, tidak komersial, dan berfungsi memberikan layanan untuk kepentingan masyarakat. Lembaga Penyiaran Publik terdiri atas Radio Republik Indonesia dan Televisi Republik Indonesia yang stasiun pusat penyiarannya berada di ibukota Negara Republik Indonesia. Di daerah provinsi, 
kabupaten, atau kota dapat didirikan Lembaga Penyiaran Publik lokal. Sumber pembiayaan Lembaga Penyiaran Publik berasal dari: iuran penyiaran; Anggaran Pendapatan dan Belanja Negara atau Anggaran Pendapatan dan Belanja Daerah; sumbangan masyarakat; siaran iklan; dan usaha lain yang sah yang terkait penyelenggaraan penyiaran.

Dalam praktiknya, keberadaan LPP TVRI dan RRI sebagai lembaga negara tidak sepenuhnya bisa diakomodasi ke dalam model kelembagaan negara struktural dan nonstruktural yang telah tersedia. Akibatnya, secara internal upaya penataan SDM dan pengelolaan keuangan menjadi terhambat. Secara eksternal, riset yang dilakukan Retno Intani menemukan masih terdapat intervensi yang kuat dari pemerintah dan parlemen terhadap manajemen TVRI. Proses rekrutmen dan pengambilan keputusan manajemen puncak TVRI: Dewan Pengawas dan Dewan Direksi, kerapkali mendapat campur tangan kekuatan politik dan ekonomi yang menggerus independensinya sebagai LPP (Intani, 2012).

Transformasi sumber daya manusia di kedua lembaga dari aparatus pemerintah menjadi broadcaster profesional tidak berjalan mulus karena regulasi yang menjadi payung kebijakan tidak bersifat tunggal dan final. Status mayoritas pekerja RRI dan TVRI sebagai pegawai negeri sipil dengan paradigma kinerja administratif yang melindungi mereka melalui UU Kepegawaian Negara, tidak sinkron dengan tuntutan budaya kerja kreatif, model reward and punishment yang harusnya dianut RRI dan TVRI selaku institusi penyiaran. Semua ini bersumber dari teks regulasi pada UU 32/2002 yang masih terlalu umum, abstrak. Diperlukan regulasi yang lebih rinci dan tidak membuka peluang interpretasi oleh institusi yang dapat memengaruhi prinsip dasar LPP, misalnya oleh adanya ketentuan peraturan pemerintah di bawah UU.

Hingga Oktober 2013, proses pembahasan RUU Penyiaran masih berlangsung dan akan memengaruhi secara signifikan nasib RUU khusus LPP usul inisiatif DPR, yang sementara ini disebut RUU Radio Televisi Republik Indonesia (RTRI). Kalangan internal RRI dan TVRI bersama kelompok masyarakat sipil menyambut antusiasi inisiatif Komisi I DPR untuk membuat RUU RTRI, dan pada saat yang sama sangat khawatir, pembahasan RUU tersebut akan mengalami penundaan oleh hajat besar Pemilu 2014.

Memasuki masa-masa Pemilu 2014, terdapat kondisi krusial yang patut dicermati: privatisasi dan "kolonialisasi baru" ruang publik oleh kepentingan politik dan ekonomi pragmatis yang diperagakan kekuatan-kekuatan dominan yang berselingkuh: kekuatan pemodal besar/konglomerat media dengan hasrat/ambisi politik Pemilu 2014. 
Akibatnya, bukan hanya penyempitan ruang publik yang egaliter, tetapi peminggiran posisi publik selaku stakeholders utama media penyiaran. Mereka terdegradasi menjadi komoditas dan konstituen pasif yang dijejali informasi manipulatif.

Siaran pers Rumah Perubahan LPP, organisasi nonprofit yang dikelola aktivis penyiaran, akademisi, dan jurnalis bulan Mei 2013 menyebutkan, lemahnya akses dan kontrol publik atas kepemilikan dan isi media penyiaran dikarenakan antara lain oleh dua kondisi. Pertama, kewenangan Komisi Penyiaran Indonesia yang belum paripurna sebagaimana regulator independen lainnya di negaranegara maju. Hambatan struktural pemerintah dan perlawanan kultural dari pelaku penyiaran masih kerapkali terjadi. Kedua, keberadaan lembaga penyiaran publik dan penyiaran komunitas di tingkat pusat dan daerah yang belum sepenuhnya kuat, independen, dan profesional. Perhatian para pihak terhadap transformasi kelembagaan, isi, dan SDM sangat kurang padahal kedua jenis lembaga penyiaran berpeluang menjadi ruang publik yang memberi pencerahan politik dalam jangka pendek (menyongsong Pemilu 2014) dan menjadi ruang interaksi seluruh kepentingan publik yang setara dalam jangka panjang (RPLPP, 2013).

UU Penyiaran No. 32/2002 baru berhasil menata arsitektur penyiaran di ranah kelembagaan dan regulator independen. Sistem kerja, kewenangan, road map transformasi semua jenis media penyiaran menuju terbangunnya iklim penyiaran yang demokratis belum diatur secara rinci, menjadi "ruang kosong” yang membuka peluang intervensi kepentingan liberalistik atas nama free market. Dalam kondisi yang tidak imbang antara penyiaran komersial dengan penyiaran publik dan komunitas, maka perhatian serius perlu ditujukan kepada penyiaran publik dan komunitas, melalui kewenangan regulasi UU yang ada pada Dewan Perwakilan Rakyat. Seirama dengan proses pergantian UU Penyiaran 32/2002, maka gagasan untuk membuat undang-undang tersendiri bagi lembaga penyiaran publik perlu diwujudkan dengan langkah-langkah nyata: membuat draft RUU LPP, pendaftaran dalam Prolegnas 2013, pembahasan, hingga penetapan yang bisa dilakukan bersamaan waktu dengan penetapan UU Penyiaran baru.

\section{Penutup}

Hingga bulan Oktober 2013, draft RUU Penyiaran sudah memasuki tahap diskusi daftar inventarisasi masalah (DIM) antara pemerintah dengan DPR. Perbedaan yang mencolok antara draft dan DIM RUU versi pemerintah dengan RUU-DIM versi DPR sangat mengkhawatirkan, terutama sikap pemerintah (Kemenkominfo) untuk menutup peluang adanya RUU khusus 
bagi LPP, bersikukuh agar LPP cukup diatur dalam PP. Pada tahap ini, suara dan sikap publik selaku pihak ketiga dan paling berkepentingan harus mendapat tempat yang layak, sikap masyarakat sipil harus jelas, fokus, dan komprehensif. Untuk itu, sangat diperlukan draft dan DIM RUU Penyiaran versi publik.

Keberadaan dan urgensi regulasi khusus bagi LPP di Indonesia harus dipahami dalam dua konteks. Pertama, proteksi dan garansi atas keberadaan LPP, meliputi RRI, TVRI dan penyiaran publik lokal sebagai sistem media massa yang menggunakan ranah publik. Kedua, kejelasan road map transformasi, revitalisasi RRI dan TVRI, integrasi keduanya ke dalam ranah manajemen media yang berstandar internasional. Kendala-kendala internal dan eksternal di tubuh LPP harus bisa dikanalkan resolusinya pada regulasi khusus tersebut. Untuk melahirkan regulasi yang mengandung kedua hal tersebut, maka semua pihak harus mau belajar, memberikan atensi yang mendalam terhadap LPP, khususnya RRI dan TVRI sebagai aset bangsa yang strategis di masa mendatang.

\section{Daftar Pustaka}

Dominick, Yoseph R. 2001. Broadcasting, Cable, the Internet and Beyond, An Introduction to The Modern Electronic Media, Singapore: Mcgrawhill Book \& Co.

Intani, Retno. 2012. Reinventing and Implementation Amidst Its Signification as A Public Television: A Case Study of TVRI as $\quad A \quad P B I$. Disertasi $\mathrm{S} 3$. Universitas Padjajaran, Bandung.

Kitley, Philip. 2000. Television, Nation and Culture in Indonesia. Jakarta: ISAI.

Komisi Penyiaran Indonesia Pusat. 2013. Kedaulatan Frekuensi, Regulasi Penyiaran, Peran KPI dan Konvergensi Media. Jakarta: Gramedia.

Masduki. 2007. Regulasi Penyiaran, Dari Otoriter ke Liberal. Yogyakarta: Penerbit LKiS.

McQuail, Denis. 1994. Mass Communication Theory, An Introduction, Third Edition. London: Sage Publication.

Mendel, Toby. 2000. Public Service Broadcasting: A Comparative Legal Survey, Kuala Lumpur: AIBD-UNESCO.

Rumah Perubahan Lembaga Penyiaran Publik, Siaran Pers, Mei 2013.

Undang-Undang Nomor 32 Tahun 2002

Tentang Penyiaran. 
Jurnal komunikasi, Volume 7, Nomor 2, April 2013 